\title{
EARLY DIAGNOSIS IN CEREBRAL PALSY- ACTUAL SITUATION IN SPAIN AND WAYS OF IMPROVEMENT
}

Martínez Arroyo EC1 ${ }^{1}$, Valero Sanz L2 ${ }^{2}$ Mas Martínez E³ ${ }^{3}$ Navarro Martínez M${ }^{4}$

${ }^{1}$ Hospital Universitario de Donostia, San Sebastian, 2University Hospital Universitario Principe de Asturias, Alcalá de Henares. ${ }^{3}$ Hospital Arnau de Vilanova, Valencia, 4Hospital Clínico Universitario, Valladolid. Spain.

\begin{tabular}{|l|}
\hline \multicolumn{1}{|c|}{ Introduction } \\
\hline The prevalence of cerebral palsy \\
is 2.1 cases per 1.000, which \\
suppose the most common \\
physical disability in childhood. \\
Etiology remains still unclear in \\
$80 \%$ of cases, but new studies \\
suggests a genetic component in \\
$14 \%$ of cases.
\end{tabular}

\section{Purpose}

Due to the variability existing in the age of the diagnosis of cerebral palsy in different countries, we carried out this study to know at what age cerebral palsy is diagnosed in our environment/country and the tools commonly used.

\section{Material and Methods}

Multi-centric observational study ${ }_{0,2}$ through an online survey to different professionals in relation with the diagnosis and treatment of the cerebral palsy.

In this survey, we asses the age at which cerebral palsy is diagnosed in our country, at what age an early diagnosis could be made, what tools are usually used for diagnosis and we also analyze in there are differences in the answers obtained according to speciality.

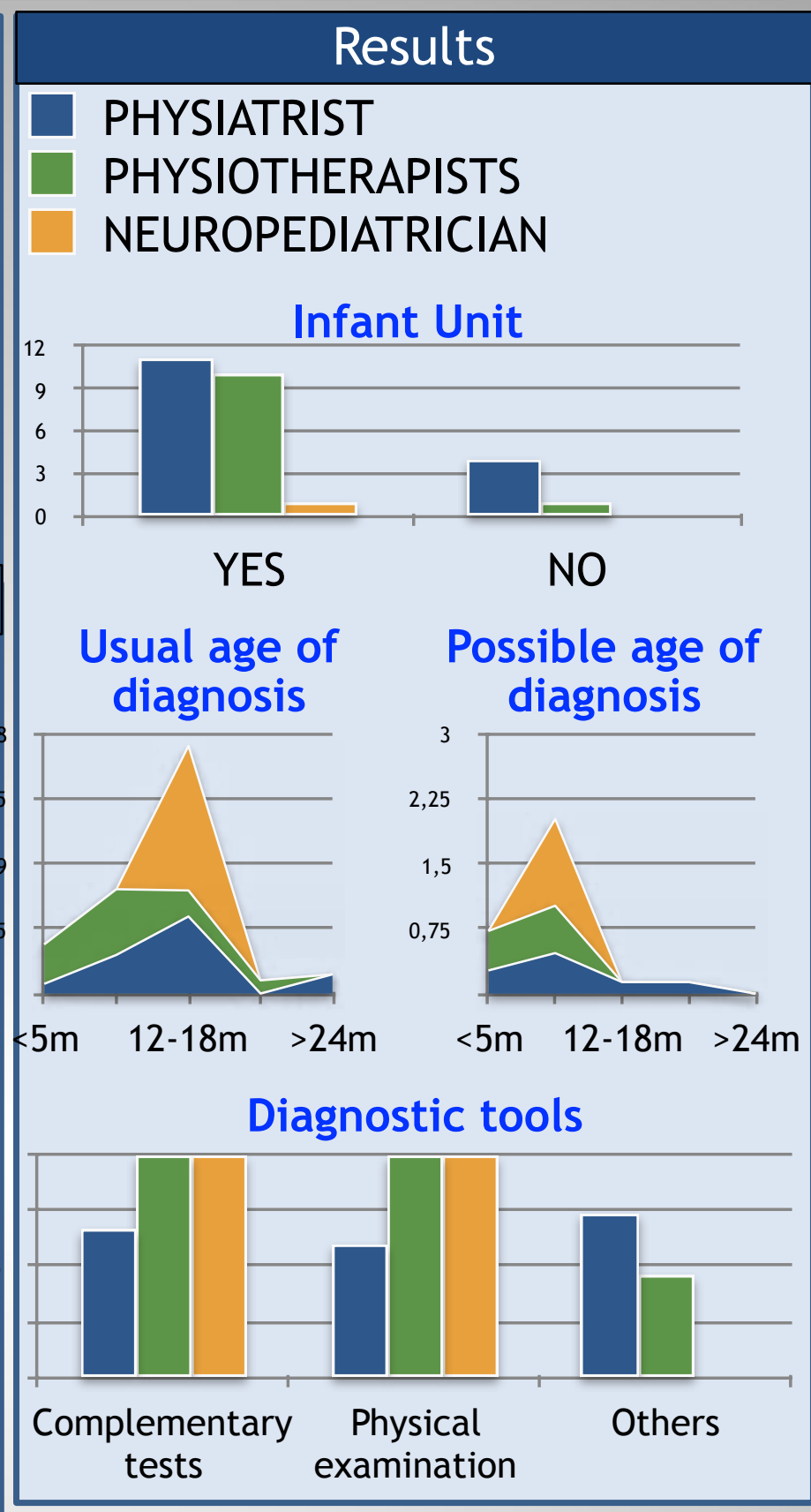

Conclusions

- Early diagnosis of cerebral palsy allows earlier intervention optimizing neuroplasticity and functional outcomes.

- There are different standardized tools that demonstrate that an early diagnosis is possible and that we should use in our daily clinical practice.

\section{References}

Novak I, Morgan C, Adde L, Blackman J, Boyd RN, Brunstrom-Hernandez J, et al. Early, Accurate diagnosis and Early Intervention in Cerebral Palsy. Advances in Diagnosis and Treatment. JAMA Pediatr. 2017 Sep 1;171(9):897-907.

Romeo DM, Ricci D, Brogna C, Mercuri E. Use of the Hammersmith Infant Neurological Examination in infants with cerebral palsy: a critical review of the literature. Dev Med Child Neurol. 2016 Mar; 58(3):240-5. 